\title{
Relationship Between Post-Pubertal Mumps Infection In Males With Infertilityand Its Effect on The Result of Seminal Fluid Analysis and Occurrence of Immunological Infertility
}

\author{
Sahar Mohammed Zaki Abdullah (MBChB, MSc) ${ }^{1}$
}

\section{Abstract}

Background: Mumps caused by paramyxovirus in the same group as parainfluenza and Newcastle disease virus, orchitis is the widely recognized complication in post-pubertal males. Approximately $50 \%$ of patients with orchitis have some degree of testicular atrophy, but sterility is rare.

Objective: To demonstrate the effect of the post-pubertal mumps infection on the result of seminal fluid analysis and to know if infection by mumps after puberty can lead to immunological infertility and production of anti-sperm antibodies.

Patients and Methods: Cross-sectional study in which 300 infertile males attending microbiology laboratory in Rizgary teaching hospital in Erbil city in Iraqi Kurdistan from November 2017- September 2018. Questionnaire was prepared for each male which included: name, age, occupation, history of mumps infection after puberty. Seminal fluid collected from each patient after 3 days of abstinence and analyzed according to WHO guidelines. Seminal fluid and serum obtained from each infertile male for the detection of anti-sperm antibodies by ELISA (enzyme-linked immunosorbent assay).

Results: The mean age of the participant in the study was (32.805 year) with the maximum and minimum age was $(50,18)$ years respectively. The incidence of post-pubertal mumps was $(13.3 \%)$ and the incidence of abnormal seminal fluid analysis was (10\%) and the highest abnormal seminal fluid variables among infertile males with post-pubertal mumps was oligoasthenozoospermia (43\%) and the anti-sperm antibodies in the semen of infertile males with post-pubertal mumps infection was $(60 \%)$ while the frequency of anti-sperm antibodies in the serum in infertile males with a history of post-pubertal mumps was (40\%) which was higher than those with no history of post-pubertal mumps with highly significant relation statistically.

Conclusion: Abnormal seminal fluid analysis result may be due to post-pubertal mumps and it can lead to (Asthenozoospermia, Oligospermia, and Teratozoospermia). The highest percentage of abnormal seminal fluid variables was Oligoasthenozoospermia the occurrence of anti-sperm antibodies can be the sequence of post-pubertal mumps and by itself can lead to abnormality in the seminal fluid analysis. Mumps can lead to male infertility by affecting the seminal fluid parameters and also by the production of anti-sperm antibodies which can lead to subfertility in adult males.

Keywords: Paramyxovirus, post-pubertal mumps, anti-sperm antibodies

Corresponding Author: Sahar.zaki@hmu.edu.krd 
Received: $14^{\text {th }}$ August 2020

Accepted: $21^{\text {th }}$ September 2020

DOI:https://doi.org/10.26505/DJM.19025500814

\section{Introduction}

Mumps is an infectious viral disease that often results in painful swelling of the parotid gland. The virus is an RNA virus of the genus paramyxovirus which is disseminated from the human reservoir by direct contact, airborne droplets, fomites contaminated by saliva, and possibly by urine. The microbiological diagnosis is by serology or virus culture. Enzyme immunoassay for mumps immunoglobulin antibodies is most commonly utilized for detection of the virus. Antibodies (IgM) are detectable in the first few days of the ailment and are viewed as indicative. Likewise, seroconversion or a fourfold increment in $\mathrm{IgG}$ titer is additionally analytic [1].

The term 'mumps' gotten from an Old English verb meaning 'grimace', mirroring the impact of parotitis on facial expression [2]. The virus has no animal reservoirs and is simply a human illness. There is only one serotype of the virus, which can be moreover separated into 10-11 genotypes [3]. People always obtain long -life immunity when infected [4]. Complications of mumps comprise: orchitis, oophoritis, aseptic meningitis, encephalitis, deafness, and pancreatitis, and at least one of these happen in up to $42 \%$ of patients with mumps [5], newly, there has been a resurgence in mumps orchitis, with epidemics being recorded every now and again $[5,6]$.

In the pre-vaccine time mumps was described by between pandemic periods each 4-5 years that most commonly affected children aged 5-7 years [7,8]. Internationally, 290 cases per year per 100000 population were diagnosed between 1977 and 1985[9]. Since the introduction of the measles-mumps-rubella (MMR) vaccine in 1968, there has been a $99 \%$ decrease in the rate of the virus infection in the USA [10]. As of late, there has been a worldwide resurgence of mumps and ongoing episodes have primarily influenced youths and young adults [11].

Mumps orchitis recently seldom observe in children less than 10 years [12]. Orchitis is the most widely recognized complication of mumps in post-pubertal men, influencing about $20 \%-30 \%$ of cases [13] 10\%-30\% are bilateral [14].

Up to $30-40 \%$ of mumps infections are subclinical, and orchitis can occur without parotid involvement [15]. Recent data show that primary mumps infection among adults directly leads to infertility $[16,17]$. The consequence of the physiological events that occur between mumps virus primary infection and the development of infertility is not fully known [18]. It is not known whether mumps orchitis is purely a viral disease or a virus-induced immunopathological disorder [19]. There are reports that the mumps virus causes infertility without the involvement of orchitis [20] and they find many male infertility cases with decreased testosterone and a history of mumps infection and mild testicular pain during their mumps infection 
[21]. Anti-sperm antibodies have for the most part been found in homosexual males and in cases of testicular trauma, varicocele, mumps or orchitis, spinal cord injury, congenital absence of the vas and vasectomy [22].

Aims of this study are: to know the effect of the post-pubertal mumps infection on the result of seminal fluid analysis also to reveal if post-pubertal mumps infection can lead to immunological infertility and production of anti-sperm antibodies.

\section{Patients and Methods}

A cross-sectional study achieved in the microbiology laboratory in Rizgary teaching hospital in Erbil city/ Iraqi Kurdistan in the period from November 2017- September 2018. 300 infertile males were included in the study, a complete questioner form prepared for each person included: name, age, address, occupation, both medical and surgical history, and history of mumps and orchitis after puberty.

A semen specimen was collected after 3 days of abstinence period, in a wide -mouth, clean and sterile container, and each patient had been told to urinate before semen collection to decrease contamination of semen from debris or leukocyte. The seminal fluid specimens were collected by masturbation after 3 days of abstinence and Semen analysis was performed following the standard procedures recommended by the World Health Organization (23). A macroscopic and microscopic evaluation of the semen was performed within 30 minutes of liquefaction time after ejaculation at 37C and processed immediately after complete liquefaction. Following the liquefaction of semen, the wet sample was first analyzed by putting $10 \mu \mathrm{l}$ of semen onto a glass slide and covered with a coverslip.

Around 200 spermatozoa in 5 fields at 40x magnification were counted for calculating the percentage of motility under four classes as the motility of each spermatozoon graded $\mathrm{a}, \mathrm{b}, \mathrm{c}$, or $\mathrm{d}$ according to their motility.

a- rapid progressive forward motility

b- slow or sluggish motility

c- non- progressive motility

d- Immotile

Sperm counting was done by utilizing a modified Neubauer counting chamber after $1 \mathrm{ml}$ of semen diluted with $19 \mathrm{ml}$ of buffer formal saline applied to the outer edges of the coverslip on each side of the chamber using the pasture pipette.

The sperm concentration and the total count were calculated in the following way: Counted sperm in five small squares X 20 dilution. Sperm morphology was studied on Papanicolaou stained smears, counting at least 200 spermatozoa utilizing $100 \times$ magnification oil-immersing lenses. Sperm vitality was surveyed in wet mount smears after staining with Eosin. After the seminal fluid analysis was classified to normal and abnormal according to $\mathrm{WHO}$ guideline and then classified to different seminal fluid variables also according to WHO guidelines [32].Serum and semen collected from infertile males for detection of antisperm antibodies by utilizing ElISA (enzymelinked immunosorbent assay) used for detection ASAs in the serum and seminal fluid of infertile males qualitatively.

\section{Statistical analysis}

The data obtained in this study analyzed by using Microsoft Windows 10 and Excel 
program and SPSS(Statistical Package for the Social Sciences) version 23. The chi-squared test applied using the SPSS programming (version 23) to determine the relation between post-pubertal mumps infection and the occurrence of anti-sperm antibodies in the serum and seminal fluid, and P-value of < 0.05 was regard as the significance level while the value $<0.001$ regarding highly significant (HS).

\section{Results}

This study shows that among 300 infertile males the incidence of males with of history post-pubertal mumps infection was 40 males which represent about $(13.3 \%)$ as shown in Figure (1).

\section{Incidence of postpubertal mumps among infertile males in Erbil city}

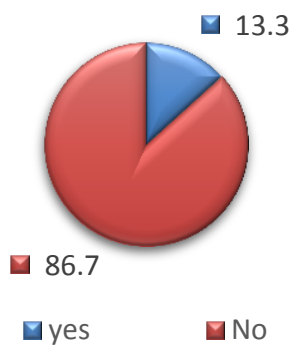

Figure (1): Incidence of post-pubertal mumps among infertile males

Table (1) shows that the result of seminal fluid variables among males with a history of mumps after puberty revealed that $10(3.3 \%)$ were normal while $30(10 \%)$ were abnormal and the relation between seminal fluid analysis and history of mumps after puberty statistically was highly significant $(\mathrm{P}$ value $=$ 0.0001).

Table (1): Relationship between result of seminal fluid analysis and history of post-pubertal mumps

\begin{tabular}{|c|c|c|c|c|c|}
\hline & & & \multicolumn{2}{|c|}{ SFA } & \multirow[t]{2}{*}{ Total } \\
\hline & & & Normal SFA & $\begin{array}{c}\text { Abnormal } \\
\text { SFA }\end{array}$ & \\
\hline \multirow{4}{*}{$\begin{array}{l}\text { History of } \\
\text { mumps }\end{array}$} & \multirow[t]{2}{*}{ Yes } & Count & 10 & 30 & 40 \\
\hline & & $\%$ of Total & $3.3 \%$ & $10.0 \%$ & $13.3 \%$ \\
\hline & \multirow[t]{2}{*}{ No } & Count & 148 & 112 & 260 \\
\hline & & $\%$ of Total & $49.3 \%$ & $37.3 \%$ & $86.7 \%$ \\
\hline \multirow{2}{*}{\multicolumn{2}{|c|}{ "Total }} & Count & 158 & 142 & 300 \\
\hline & & $\%$ of Total & $52.7 \%$ & $47.3 \%$ & $100.0 \%$ \\
\hline
\end{tabular}

*P value: 0.00

Table (2) which shows the relationship between the history of infection by mump after puberty with seminal fluid variables and this study that highest percentage of the seminal fluid variables shows that $32.5 \%$ of seminal fluid was oligoasthenozoospermia and the relation between the post-pubertal mumps infection with seminal fluid variables was statistically significant. 
Table (2): Effect of post-pubertal mumps infection on seminal fluid variables

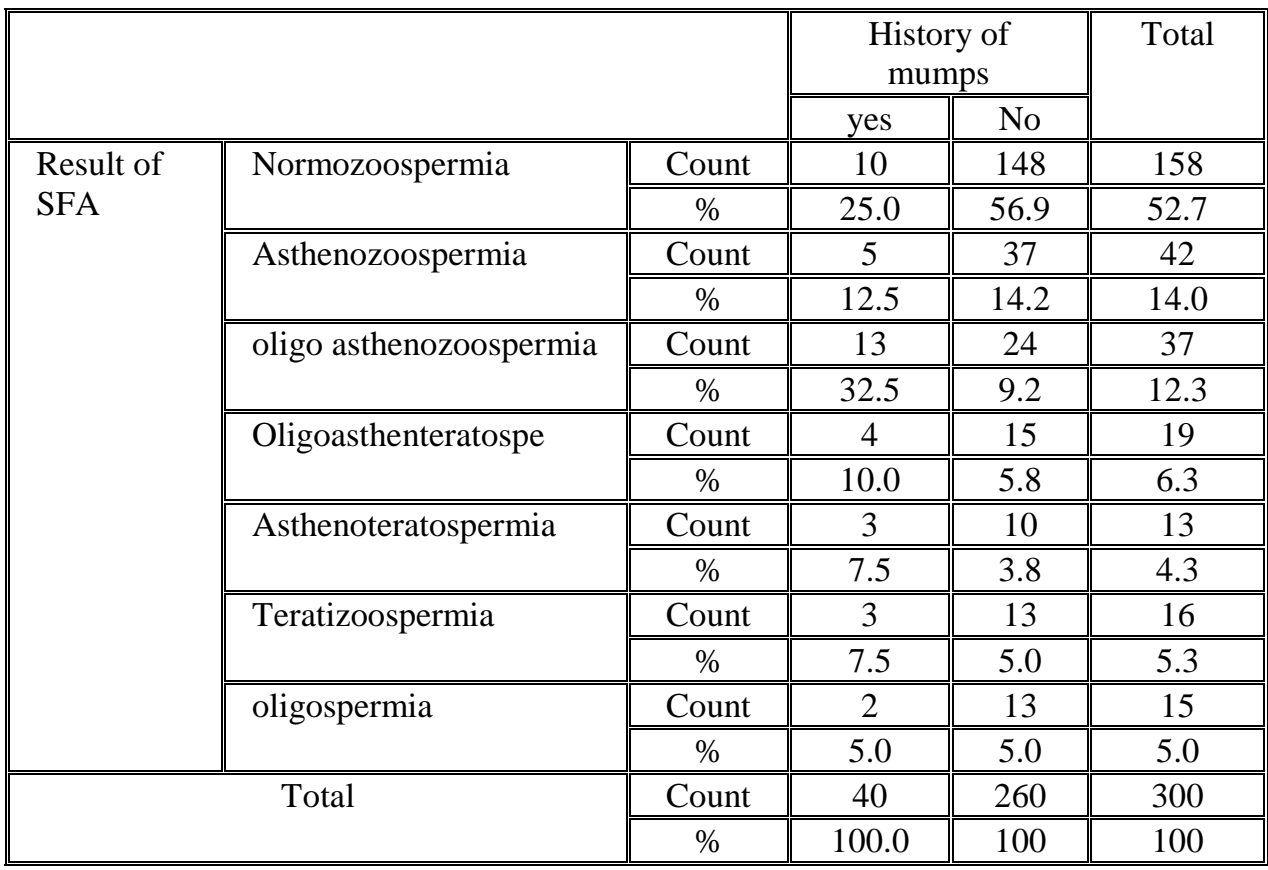

* P value: $0.000(\mathrm{HS})$

Figure (2) demonstrated only abnormal seminal fluid variables in the infertile males with post-pubertal mumps, the distribution of abnormal seminal variable was as follow. Oligoasthenozoospermia ( $43 \%$ ) followed by asthenozoospermia(17\%),oligoasthenoteratoz oospermia(13\%),asthenoteratozoospermia and teratozoospermia(10\%) and Oligospermia(7\%).

Abnormal seminal fluid varaibles among infertile males with history of post-pubertal

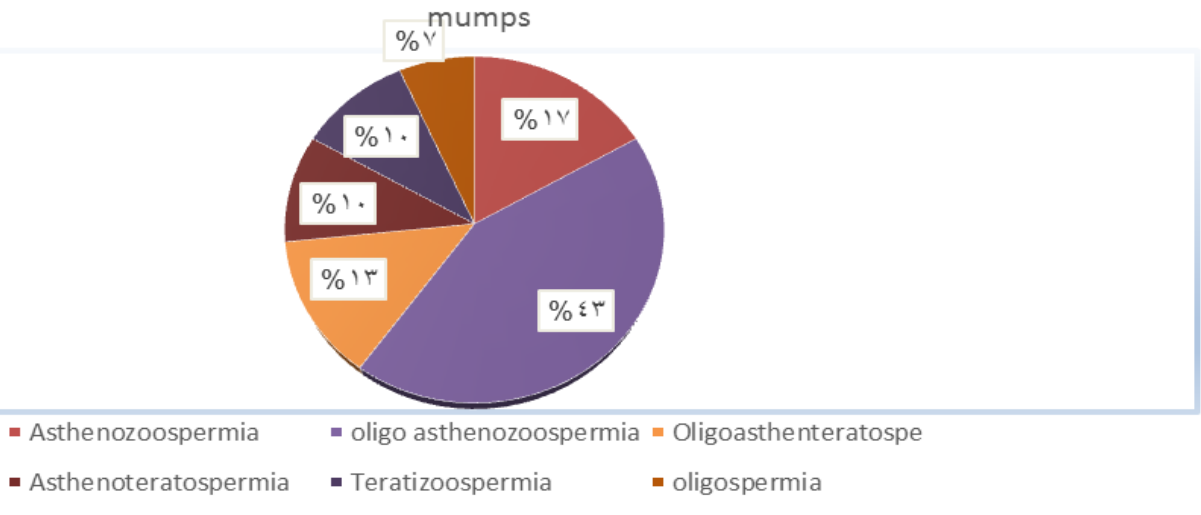

Figure (2): Abnormal seminal fluid variables among infertile males with post-pubertal mumps Table (3) revealed that the incidence of antisperm antibodies in the semen of males with a history of post-pubertal mumps infection didn't have a history of mumps after puberty $16(40 \%)$ with statically significant differences $(0.02)$. was $24(60 \%)$ which higher than those they 
Table (3): Correlation between post-pubertal mumps infection and the occurrence of anti-sperm antibodies in the semen of infertile males

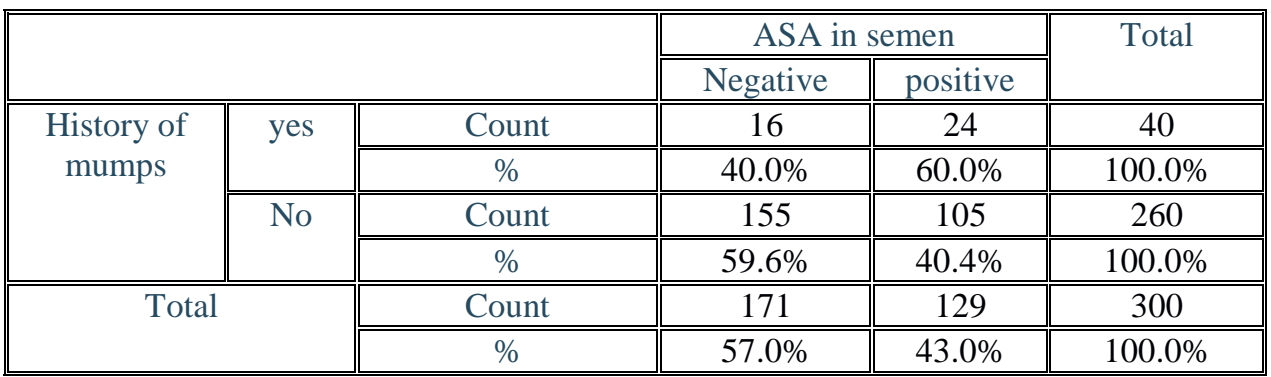

*P value: $0.020(\mathrm{~S})$

Table (4) shows that the incidence of abnormal seminal fluid with anti-sperm antibodiesin semen 66(51.2\%) which was higher than the normal result of SFS with

Table (4): Effect of anti-sperm antibodies on the result of seminal fluid analysis

\begin{tabular}{|c|c|c|c|c|c|}
\hline & & & \multicolumn{2}{|c|}{ SFA } & \multirow[t]{2}{*}{ Total } \\
\hline & & & $\begin{array}{c}\text { Normal } \\
\text { SFA }\end{array}$ & Abnormal & \\
\hline \multirow{4}{*}{$\begin{array}{l}\text { ASA in } \\
\text { semen }\end{array}$} & \multirow{2}{*}{$\begin{array}{c}\text { Negativ } \\
\mathrm{e}\end{array}$} & Count & 95 & $\overline{776}$ & 171 \\
\hline & & $\%$ & $55.6 \%$ & $44.4 \%$ & $100.0 \%$ \\
\hline & \multirow{2}{*}{ positive } & Count & 63 & 66 & 129 \\
\hline & & $\%$ & $48.8 \%$ & $51.2 \%$ & $100.0 \%$ \\
\hline \multirow{2}{*}{\multicolumn{2}{|c|}{ Total }} & Count & 158 & 142 & 300 \\
\hline & & $\%$ & $52.7 \%$ & $47.3 \%$ & $100.0 \%$ \\
\hline
\end{tabular}

Table(5) showed that the incidence of antisperm antibodies in serum in those they had a history of post-pubertal mumps $16(40 \%)$ which higher than the incidence of positive ASAs in semen, this relation was statistically non-significant (p-value: $0.49)(\mathrm{NS})$.
Table (5): Correlation between history of post-pubertal mumps infection and the occurrence of antisperm antibodies in the serum of infertile males

\begin{tabular}{|c|c|c|c|c|c|}
\hline & & & \multicolumn{2}{|c|}{ Serum ASA } & \multirow[t]{2}{*}{ Total } \\
\hline & & & Negative & Positive & \\
\hline \multirow{4}{*}{$\begin{array}{l}\text { History of } \\
\text { mumps }\end{array}$} & \multirow[t]{2}{*}{ yes } & Count & 24 & 16 & 40 \\
\hline & & $\%$ & 60.0 & 40.0 & 100.0 \\
\hline & \multirow[t]{2}{*}{ No } & Count & 213 & 477 & 260 \\
\hline & & $\%$ & 81.9 & 18.1 & 100.0 \\
\hline \multirow{2}{*}{\multicolumn{2}{|c|}{ Total }} & Count & 237 & 63 & 300 \\
\hline & & $\%$ & 79.0 & 21.0 & 100.0 \\
\hline
\end{tabular}

*P value: $0.002(\mathrm{HS})$
Table (6) shows that abnormal seminal fluid was higher among those with ASAs in serum was $38(26.8 \%)$ which was higher than the
ASAs in serum with no history of postpubertal mumps $47(18.1 \%)$ and this relation statistically was highly significant(P-value: $0.002)$. normal result of seminal fluid analysis with positive ASAs in serum, this relation was statistically non-significant (P-value: 0.49). 
Table (6): Correlation between ASAs in serum with the result of seminal fluid analysis

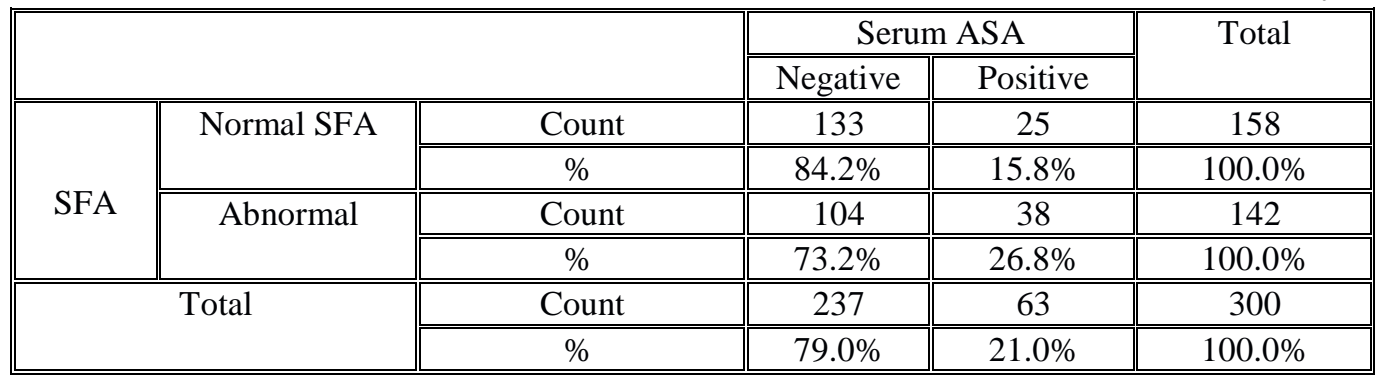

\section{Discussion}

Mumps is a viral infections illness caused by the mumps virus, early signs and symptoms often include fever, muscle pain, headache, poor appetite, and feeling commonly unwell, this is then usually followed by painful swelling of one side or both sides of parotid salivary glands [24]. Manifestations of the disease are frequently more extreme in adults than in children, complications may include meningitis, pancreatitis, carditis, permanent

deafness, and orchitis which can lead to male infertility[25].

Mumps virus has high tropism to the testis and may prompt male infertility. Sertoli cells are the significant focuses of Mumps virus infection. In any case, the mechanisms by which Mumps infection impairs male fertility and Sertoli cell function still not clear [26].

The result of this study revealed the incidence of post-pubertal mumps among infertile males in Erbil City was (13.3\%) and this in agreement with a study done by (Niall et al) whom estimated that subfertility is occurred in $13 \%$ of mumps patients, and can occur in patients with no signs of testicular atrophy or orchitis [15]. Orchitis is viewed as the most well-known complication of mumps infection in the adult male. Orchitis usually follows parotitis but may occur before or happen without parotid gland swelling.

Orchitis generally shows up during the primary seven days of parotitis, however, it can happen in the second or third week, and both side orchitis occurs less frequently (about 10\% of cases) [27]. Also, our result was in agreement with a study by (Masarani et al) who stated that deterioration of fertility is predestined to happen in about $13 \%$ of patients with mumps orchitis may, and it can also can result in oligospermia, azoospermia, and asthenozoospermia (defects in sperm movement) [28].

Orchitis (testicular inflammation) is the most well-known complication in postpubertal males. In the pre-vaccine period, orchitis was manifest in $12 \%$ to $66 \%$ of postpubertal males infected with mumps. In $60 \%$ to $83 \%$ of males with mumps orchitis, just one testis was affected. Orchitis usually follows parotitis, but it may occur before it, begin at the same time, or it happens alone [29]. In this study, the result of seminal fluid variables among males with history of mumps after puberty revealed that $30(10 \%)$ were abnormal and the relation between seminal fluid analysis and a history of mumps after puberty statistically was highly significant $(P$ value $=0.0001)$ and this result 
was lower than [30] which stated that $24 \%$ of adults had semen abnormalities.

This study demonstrated that there was a significant relationship between the result of seminal fluid analysis and the occurrence of post-pubertal mumps infection in which the abnormal seminal fluid was higher in those with a history of post-pubertal mumps than normal seminal fluid analysis and the percentage of abnormal seminal fluid variables was as follow Oligoasthenozoospermia ( $43 \%$ ) followed by asthenozoospermia $(17 \%)$ oligoasthenoteratozoospermia(13\%), asthenoteratozoospermia teratozoospermia(10\%) and oligozoospermia was the lowest was Oligospermia (7\%). The result of this study regarding Oligoasthenozoospermia was higher than those reported by (Cavallini) which was (12.4\%), regarding asthenozoospermia, asthenoteratozoospermia and teratozoospermia was similar to our result which was(18.2\%, 9.1\%,9\%) respectively while regarding Oligospermia our result was lower than reported by [31] which was $(63.4 \%)$.

Oligoasthenoteratozoospermia is viewed as a serious variation from the norm related to the quality and amount of semen [29]. Men with severe oligoasthenoteratozoospermia have a decrease in the number of cells in their ejaculate, decreased total motility, minimum progressive forward motility, and a decrease in the number of sperms with normal morphology [32].

Our result was in agreement with a study done by [33] who showed that the semen analysis showed $100 \%$ greatly reduced sperm count, and severe abnormalities in motility and morphology which confirms the mumps virus may be the possible reason for infertility in males with postbupertal mumps[33].

The prevalence of anti-sperm antibodies in infertile males with a history of post-pubertal mumps was higher than those with no history of post-pubertal mumps and the incidence of ASAs with abnormal SFA was higher than those with negative ASA in the semen.

The exact mechanism by which the mumps virus elicited anti-sperm antibodies is unknown, although animal models have shown that acute orchitis may be a causative factor in anti-sperm antibody production, towards sperm can prevent their motility via the female reproductive tract or prevent the procedure of fertilization [34].

Immunologic factors are considered as a significant reason for infertility [35]. One of the immunologic factors proposed for infertility is the presence of anti-sperm antibodies in serum. Anti-sperm antibodies are found in cervical mucus, seminal plasma and serum of men and women [36]. Immunity to sperm can be a result of infertility; humoral antibodies coordinated against sperm did not necessarily debilitate fertility unless the circulating antibodies are also found within the reproductive tract and on the living sperm surface [37].

Immunological infertility is thought to be the reason of infertility in $9-36 \%$ of the concerned couples. The main cause of immunological infertility is the production of anti-sperm antibodies (ASA), which influence the ability of fertilization of spermatozoa [38]. 
ASA may diminish the motility of spermatozoa through agglutination and immobilization, thus preventing sperm movement through the female genital tract. A lowering in sperm motility has been seen by the different researchers as well in anti-sperm antibodies positive males [39].

The causal relation between mumps orchitis and anti-sperm antibodies has been indistinct, in spite of the fact that the antibodies were suspected to debilitate fertility, [Kalaydjiev et al.] shown that both the occurrence and the degree of serum antisperm antibodies among mumps orchitis patients were low, and did not bolster the theory of an enhanced humoral immunity towards spermatozoa[18].

In reports found that human seminal ASAs exert unwanted effects on sperm quality by changing important semen parameters, many paradoxical scientific papers exist; some of them emphasize that ASAs influence major semen parameters as specified by statistically significant differences in the semen parameters between ASA groups and fertile groups without ASAs as recordedrt4es by [40].

\section{Conclusions}

The post-pubertal mumps infection can influence the result of seminal fluid analysis and can result in abnormal seminal fluid analysis results. The production of anti-sperm antibodies can be the sequence of postpubertal mumps and by itself can lead to abnormality in the seminal fluid analysis and mumps can lead to male infertility by affecting the seminal fluid parameters and also by the production of anti-sperm antibodies which can lead to subfertility in the adult male.

\section{Recommendations}

Parents and communities ought to be made interested that neglecting to vaccinate their children undermines the future fertility of their children. Young men not immunized as kids ought to be directed and offered pressing immunization. We need more concentration on this virus and its relation with unexplained infertility because we have a small number of studies which concentrate on this issue.

\section{References}

[1]Rubin S, Eckhaus M, Rennick LJ, Bamford CG, Duprex WP. Molecular biology, pathogenesis and pathology of mumps virus. J Pathol. 2015; 235(2): 242-52. [2]Senanayake SN. Mumps: a resurgent disease with protean manifestations. Med J Aust 2008; 189: 456-59.

[3]Mühlemann K. The molecular epidemiology of mumps virus. Infect Genet Evol. 2004; 4(3): 215-19.

[4]Harling R, White JM, Ramsay ME, Macsween KF, van den Bosch C. The effectiveness of the mumps component of the MMR vaccine: a case control study. Vaccine. 2005; 23: 4070-4.

[5]Clemmons NS, Redd SB, Gastañaduy PA, Marin M, Patel M, Fiebelkorn AP. Characteristics of Large Mumps Outbreaks in the United States, July 2010-December 2015, Clinical Infectious Diseases. 2019; 68 (10): 1684-90.

[6]Dayan GH, Quinlisk MP, Parker AA, Barskey AE, Harris ML, Jennifer M, et al. Recent resurgence of mumps in the United States. N Engl J Med. 2008; 358(15): 158089. 
[7]White SJ, Boldt KL, Holditch SJ, Poland GA, Jacobson RM. Measles, mumps, and rubella. Clin Obstet Gynecol. 2012; 55(2): 550-59.

[8] Edmunds WJ, Gay NJ, Kretzschmar M, Pebody RG, Wachmann H. The prevaccination epidemiology of measles, mumps and rubella in Europe: implications for modelling studies. Epidemiol Infect. 2000; 125: 635-50.

[9]Urbano PR, Fujita DM, Romano CM. Reemergence of mumps in São Paulo, Brazil - the urgent need for booster shot campaign to prevent a serious infectious disease. Rev. Soc. Bras. Med. Trop. 2017; 50 (4): 535-38. [10]Anderson LJ, Seward JF. Mumps epidemiology and immunity - the anatomy of a modern epidemic. Pediatric Infectious Disease Journal. 2008; 27(10): 75-79.

[11] Gemmill I. Mumps vaccine: is it time to re-evaluate our approach?. CMAJ. 2006; 175: 491-2.

[12]Choi KM. Reemergence of mumps. Korean J Pediatr. 2010; 53(5): 623-8.

[13]Berhrman RE, Kliegman RM, Jenson HB, eds. Nelson Textbook of Pediatrics, 17th edn. Philadelphia: Saunders, 2004.

[14] Joe P, David S, Anthony DD. Mumps orchitis in the non-immune postpubertal male: A resurgent threat to male fertility?. BJU International 2006; 97: 138 - 141.

[15]Niall FD, Barry BM, Jackie AM, Anna ES, Kiaran JO, John MF. The increasing incidence of mumps orchitis: a comprehensive review. BJUI. 2010; 105: 1060-1065.

[16]Basekim CC, Kizilkaya E, Pekkafali Z, Baykal KV, Karsli AF. Mumps epididymoorchitis: sonography and color Doppler sonographic findings. Abdom Imaging. 2000; 25:322-325.

[17]Mouchel T, Le Goffic R, Patart JJ, Samson M. Mumps virus and orchitis: towards a physiopathologic approach. Prog Urol. 2002; 12(1): 124-28.

[18] Kalaydjiev S, Dimitrova D, Nenova M, Peneva S, Dikov I, Nakov L. Serum sperm antibodies are not elevated after mumps orchitis. Fertility and Sterility. 2002; 77(1): 76-82.

[19]Yapanoglu T, Kocaturk H, Aksoy Y, Alper F, Ozbey I. Long-term efficacy and safety of interferon-alpha-2B in patients with mumps orchitis. Int Urol Nephrol. 2010; 42(4): 867-71.

[20]Chandrashekar P, Sathiasekar AC, Namaratha K, Singarayan JL, Gnanam AP. A rare case of mumps orchitis. J Pharm Bioallied Sci. 2015; 7(2): 773-75.

[21]Jeevan M, Sanjeeva N, Abinaya G P. Serum Th1/Th2 Cytokine Levels During Acute Mumps Infection: Prediction To Infertility Patients with History of Mumps Infection. IOSR Journal of Dental and Medical Sciences. 2017; 6(5): 83-90. [22] Shibahara H, Shiraishi Y, Suzuki M. Diagnosis and treatment of immunologically infertile males with antisperm antibodies. Reprod Med Biol. 2005; 4(2): 133-141.

[23]World Health Organization. laboratory manual for the Examination and processing of human semen. FIFTH EDITION. WHO Library Cataloguing-in-Publication Data; Switzerland. 2010.

[24]Davis NF, McGuire BB, Mahon JA, Smyth AE, O'Malley KJ, Fitzpatrick JM. The increasing incidence of mumps orchitis: a 
comprehensive review. BJU International. 2010; 105 (8): 1060-5.

[25]Gupta RK, Best J, MacMahon E. "Mumps and the UK epidemic" . BMJ (Clinical Research Ed.). 2005; 330 (7500): $1132-5$.

[26] Wu H, Jiang X, Gao Y, Liu W, Wang F, Gong M. Mumps virus infection disrupts blood-testis barrier through the induction of TNF- $\alpha$ in Sertoli cells. FASEB J. 2019;33(11):12528-12540.

[27] Singh R, Mostafid H, Hindley RG. Measles, mumps and rubella - the urologist's perspective. Int J Clin Pract. 2006; 60(3): 335-39.

[28]Masarani M, Wazait H, Dinneen M. Mumps orchitis. J R Soc Med. 2006; 99(11): 573-5.

[29]Ternavasio-de la VHG, Boronat M, Ojeda A, Garcia-Delgado Y, Angel-Moreno A, Carranza-Rodriguez C, et al. Mumps orchitis in the post-vaccine era (1967-2009): a single-center series of 67 patients and review of clinical outcome and trends. Medicine (Baltimore). 2010; 89: 96-116. [30] Philip J, Selvan D, Desmond A D. Mumps Orchitis In The Non-Immune postpubertal male: a resurgent threat to male fertility?. BJU Int. 2006; 97(1):138-41.

[31]Cavallini G. Male idiopathic oligoasthenoteratozoospermia. As J Androl. 2006; 8: 143-157.

[32] Aydos SE, Tukun A. Infertility in a man with oligoasthenoteratozoospermia associated with nonrobertsonian translocation. Fertil Steril. 2006; 86: 7-9. [33]Malaiyan J, Nellapillai SR, Ramanan PV, Gokul A. Serum Th1/Th2 Cytokine Levels During Acute Mumps Infection: Prediction to
Infertility Patients with History of Mumps Infection. IOSR. 2017; 16(5): 83-90.

[34]Fijak M, Pilatz A, Hedger MP, Nicolas $\mathrm{N}$, Bhushan S, Michel $\mathrm{V}$ etal. Infectious, inflammatory and 'autoimmune' male factor infertility: how do rodent models inform clinical practice?. Hum Reprod Update. 2018; 24(4): 416-441.

[35]Lu J, Huang Y, Lu N. Anti sperm immunity and infertility. Expert Rev Clin Immunol 2008; 4 (1): 113-126.

[36] Karimi F, Khazaei S, Alaedini F. Serum antisperm antibodies in fertile and infertile individuals. Iran J Med Sci. 2008; 33 (2): 8892.

[37] Fábio F, Antônio M, Lucon H, Plínio M, Góes B, Saldanha S. Induction of spermatogenesis in azoospermic men after varicocele repair. Hum Reprod. 2003; 18: $108-112$.

[38]Ghazeeri GS, Kutteh WH. Immunological testing and treatment in reproduction: frequency assessment of practice pattern at assisted reproduction clinics in the USA and Australia. Human Reprod. 2001; 16 (10): 2130-5.

[39]Mumuce MJ, Berta CL, Pauluzzi F, Caille AM. Relationship between anti-sperm antibodies, sperm movement and quality. Urol Int. 2000; 65 (4): 200-3.

[40] Bohring C, Krause W. Differences in the antigen pattern recognized by anti-sperm antibodies in patients with infertility and vasectomy. J Urol. 2001; 166(3):1178- 80. 